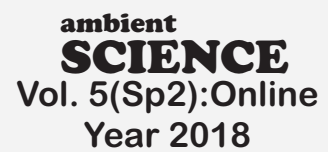

RESEARCH ARTICLE

\title{
Phytochemical Screening of Celastrus peniculatus and Sterculia urens
}

\section{Tinki Kanoje ${ }^{1}$, Kavita Sharma ${ }^{2 *}$, Jai Narayan Verma' $^{1}$}

'Department of Botany, Government Arts and Commerce Girls College Devendra Nagar, Raipur (C.G.), India

${ }^{2}$ Department of Botany, Government D.B. Girls P.G. (Autonomous) College, Raipur (C.G.), India

Study Area: Narayanpur, Chhattisgarh, India Coordinates: $19^{\circ} 43^{\prime} \mathrm{N} ; 81^{\circ} 15^{\prime} \mathrm{E}$

Key words: Herbal medicine, Secondary metabolites, TLC

Abbreviations: AQ- aqueous, AC- acetone, PE- petroleum ether, $\mathrm{CH}$-chloroform extracts, TLC-Thin Layer Chromatographic

\section{Introduction:}

Plants always served as a source of pharmaceutical products and inexpensive starting materials for the synthesis of some known drugs. Components with medicinal properties from plants play an important role also in conventional Western medicine. In 1984, at least $25 \%$ of the Western medicine issued in the US and Canada were derived from or modeled after plant natural products and 119 secondary metabolites were used globally as drugs (Farnsworth, 1994). It has been estimated that $14-28 \%$ of higher plant species are used medically. Till date, only a fraction (15\%) of total angiosperms have been chemically analyzed and $74 \%$ of pharmaceutically active plant-derived components were discovered after following up on ethnomedical use of the plant (Farnsworth \& Soejarto, 1991). In the ethnopharmacological approach, local knowledge about the potential uses of the plants is always useful. Compounds such as benzoin and emetine which inhibits destructive microorganisms have been isolated from plants (Cox, 1994). Plants are capable of synthesizing an overwhelming variety of organic compounds belonging to the low molecular weight usually unique and complex in structure. Phytochemicals produced in plants are secondary compounds responsible for metabolic activities and defensive in nature. Phytochemicals are produced by specific biochemical pathways, which occur inside the

\section{Abstract}

The phytochemical analysis of the plants is commercially very important used in the production of new drugs for curing of various diseases and to develop plants based antifungal agents and potent source of natural antioxidant drugs. The present study was carried out to determine the phytochemical constituents, Thin Layer Chromatographic (TLC) profile of economic important medicinal Celastrus peniculatus and Sterculia urens leaf extract in acetone, petroleum ether, chloroform, and aqueous extracts. Soxhlet extracts were used for the study. The qualitative phytochemical analysis of these species exhibited the presence of alkaloids, phenols, reducing sugar, saponins, tannins, terpenoids, flavonoids, fixed oils group in considerable quantity in different solvent extracts. Anthraquinones were found to be present in only aqueous extracts. TLC studies using different solvent system revealed homogenous spots with different Rf value. Various spraying agents were used as a developer in visible light.

plant cells. Till date, At least 12,00o phytochemicals (secondary metabolites) have been isolated from plants, a number estimated to be less than $10 \%$ of the total (Rawat et al., 2006). Translation of ethnobotanical information for isolation and identification of phytochemicals is required for revealing the pharmacological status of the important phytochemicals.

\section{Materials and method:}

Collection and identification of plant material: mature and fresh leaves of Celastrus peniculatus (family: celastraceae) and Sterculia urens (family: sterculiaceae) were collected from an herbal garden of Bakhrupara Kasthagar, Narayanpur district Bastar (C.G.) in the month of Nov- Dec 2015. Plants were identified by an authentic source. Leaves were washed 2-3 times with running water and once with sterile distilled water. Leaves were dried at room temperature for about 3-4 week until the leaves were brittle enough to break easily. The dried plant material was ground to fine powder using an electric grinder and stored in airtight container in a cool place until further use (Hassan et al. 2011; Debnath et al. 2012).

Preparation of extracts: crude plant extract was prepared by Soxhlet extraction method. Twenty-five grams of fine powder was filled in the thimble and extracted successively with four different solvents of $250 \mathrm{ml} v i z$., petroleum ether, 
chloroform, acetone, aqueous solution in the ascending order of polarity. The extracting solvent in a flask was heated, and its vapours were condensed in the condensers. The process of extraction was continued till the solvent in thimble tube of an extractor become colorless. Further, the extracts were filtered through Whatman No.1 filter paper. After filtration, the extracts were concentrated under low pressure at $40^{\circ} \mathrm{C}$ and were stored in an airtight sterile bottle in refrigerator for further use.

Preliminary Phytochemical Screening: the extracts obtained were subjected to following chemical tests for identification of various phytoconstituents following the methods are given by (Thilagavathi et al., 2015; Kakad \& Dhewbara, 2017) as phytochemical test (Table-1).

Thin Layer Chromatographic (TLC): the aqueous, acetone, petroleum ether, chloroform extracts were selected for TLC study. Then the extracts were taken in a micropipette and it was spotted in preparative TLC plates with Silica Gel-G. The plates were developed in TLC chamber previously saturated with solvent system petroleum ether: benzene: methanol (16:3:2). The different spots developed in each solvent system were identified by means of detecting agents like conc. $\mathrm{HCl}$ for saponins, ammonia solution for flavonoids, $\mathrm{FeCl}_{3}$ for phenol and the Rf value are correspondingly calculated. (Reddy et al., 2015; Rashid et al., 2017).

Rfvalue $=\quad \frac{\text { Distance traveled by the solute }}{\text { Distance traveled by the solvent }}$

\section{Results \& Discussion:}

Preliminary Phytochemical screening: our results revealed the presence of phytochemicals considered as active medicinal chemical constituents. Phytochemical screening and qualitative estimation of Celastrus peniculatus plant showed that the aqueous extract of leaves was rich in alkaloids, reducing sugar, saponins, tannins, terpenoids, fixed oils, and anthraquinones. Acetone extract reported the presence of alkaloids, phenols, reducing sugar, tannins and fixed oils. Petroleum ether extract reported the presence of alkaloids, reducing sugar, tannins and fixed oils. However, chloroform extract revealed the presence of reducing sugar, saponins, terpenoids and fixed oils. While Anthraquinones were found only in aqueous extract whereas the cardiac glycoside and flavonoids were absent in all the solvent extracts. The results of preliminary phytochemical analysis are tabulated in table-1. The aqueous extract of Sterculia urens showed the presence of alkaloids, reducing sugar, saponins, terpenoids, fixed oils, and anthraquinones. Its acetone extract showed the presence of alkaloids, phenols, reducing sugar, saponins, tannins, terpenoids and fixed oils. Petroleum ether extract showed the presence of alkaloids, saponins, flavonoids, fixed oils. However, in chloroform extract, only alkaloids, saponins, terpenoids, and fixed oils were evidenced.
Anthraquinones was found only in aqueous extract whereas cardiac glycoside was not found any solvent extracts.

TLC Result: the retardation fraction (Rf) of Celastrus peniculatus and Sterculia urens of different extracts in solvent system are shown in table $2 \& 3$. Photographs of the studied TLC plates are shown in fig.-3 \& 4 .

Table -1: Qualitative analysis of Phytochemical content in

C. peniculatus \& $S$. urens leaves extract in various solvents

Phytochemical (Test Performed)

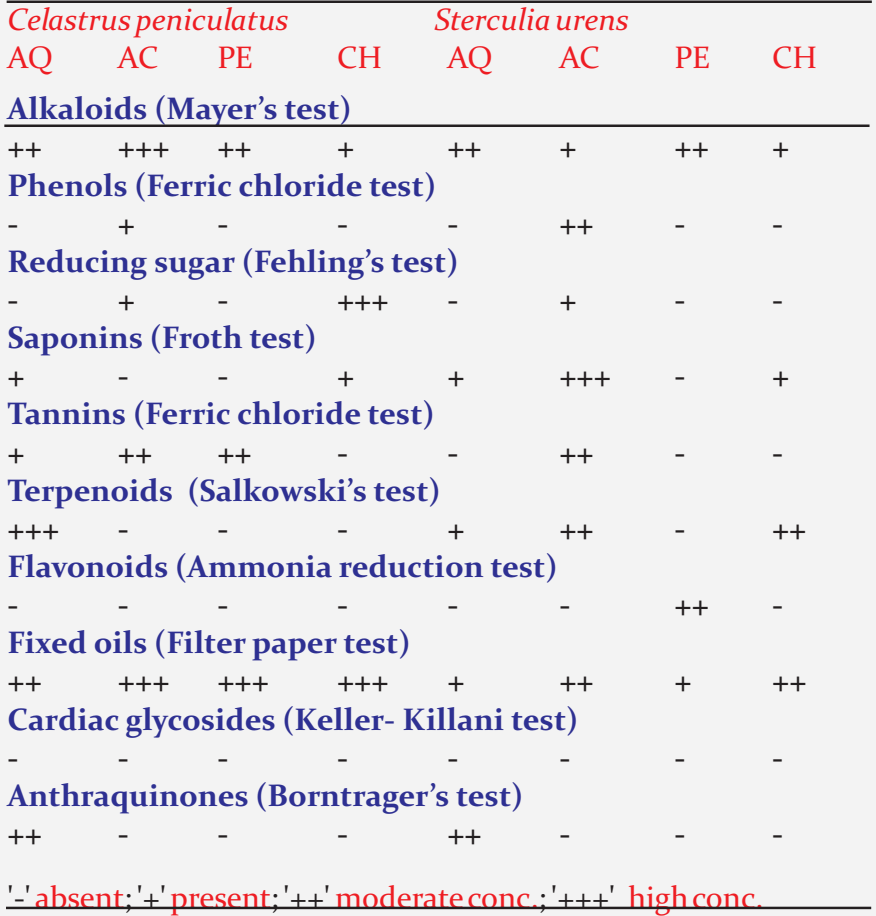

For the pharmacological study for investigate the source of novel drugs, the essential information regarding the chemical constituents is generally provided by the qualitative phytochemical screening of plant extracts. In the present study, the qualitative tests of Celastrus peniculatus's extracts indicated a significant presence for alkaloids, reducing sugar, saponins, tannins, terpenoids, fixed oils, flavonoids, phenols, and anthraquinones whereas, alkaloids, tannins, reducing sugar and fixed oils were found in the aqueous, acetone, petroleum ether, and chloroform extracts. The terpenoids, saponins, and anthraquinones content were identif ied in aqueous extract, saponins content was mainly present in water and chloroform extract and phenols were identified in acetone extract. But, flavonoids and cardiac glycoside were totally absent in all the extracts. The findings are also in line with previous findings (Deodhar \& Nandawaman, 2014; Arora \& Pandey-Rai, 2012).

In Sterculia urens alkaloids and fixed oils were found in aqueous, acetone, petroleum ether and chloroform extracts. The phenols, reducing sugar, saponins, tannins, terpenoids content were identified in acetone extract. Terpenoids, anthraquinones and saponins content were 
identified in aqueous extract. Flavonoids were mainly present in petroleum ether extract. Saponins and terpenoids were identified in chloroform extract. While cardiac glycosides were totally absent in all the extracts.

Table -2: Rf values of different compounds of C.peniculatus from development of the TLC plates using solvent systems Petroleum ether: Benzene: Methanol (16:3:2)

\begin{tabular}{|c|c|c|c|c|c|}
\hline Extracts & $\mathrm{Rf}$ & & & Appeared & Phyto \\
\hline value & bands & reagent & & bands & chemicals \\
\hline$\checkmark \mathrm{A}$ & - & - & $\mathrm{NH}, \mathrm{OH}$ & own & FlavonoidsX \\
\hline & - & - & $\mathrm{FeCl}_{3}$ & Dark & Phenols X \\
\hline & - & - & $\mathrm{HCl}$ & wn & Saponins $\mathbf{X}$ \\
\hline$\checkmark$ Ace & - & - & $\mathrm{NH}_{4} \mathrm{OH}$ & Yel & oidsX \\
\hline & 0.4782 & & $\mathrm{FeCl}_{3}$ & $\mathrm{Gr}$ & Phe \\
\hline & 0.7826 & & $\mathrm{HCl}$ & & \\
\hline$\checkmark$ Pet & 0.3 & Yellow & $\mathrm{NH}_{4} \mathrm{OH}$ & Yel & loids \\
\hline & - & - & $\mathrm{FeCl}_{3}$ & $\mathrm{Gr}$ & Phenols X \\
\hline & 0.64 & $\mathrm{Gre}$ & $\mathrm{HCl}$ & Da & Sap \\
\hline oro & - & - & $\mathrm{NH}_{4} \mathrm{OH}$ & - & noidsX \\
\hline & - & - & $\mathrm{FeCl}_{3}$ & Yell & Phenols X \\
\hline & 0.9166 & Green & $\mathrm{HCl}$ & Green & Saponins \\
\hline
\end{tabular}

$\underline{\mathrm{X} \text { - Not Detected }}$

Table -3: Rf values of different compounds of S.urens from development of the TLC plates using solvent systems Petroleum ether: Benzene: Methanol (16:3:2)

\begin{tabular}{|c|c|c|c|c|c|}
\hline xtracts & $\mathrm{Rf}$ & Visible & Spraying & Appeared & Phyto \\
\hline & value & bands & reagents & bands & chemicals \\
\hline$\checkmark$ Aqueous & - & - & $\mathrm{NHOH}$ & - & FlavonoidsX \\
\hline & - & - & $\mathrm{FeCl}_{3}$ & - & Phenols $\mathrm{X}$ \\
\hline & 0.3117 & Green & $\mathrm{HCl}^{3}$ & Dark brown & Saponins \\
\hline$\checkmark$ Acetone & - & - & $\mathrm{NH}_{4} \mathrm{OH}$ & - & FlavonoidsX \\
\hline & 0.9047 & Green & $\mathrm{FeCl}_{3}$ & Grey & Phenols \\
\hline & 0.9047 & Green & $\mathrm{HCl}$ & Dark brown & Saponins \\
\hline$\checkmark$ Petro & 0.9142 & Yellow & $\mathrm{NH}_{4} \mathrm{OH}$ & Yellow & Flavonoids \\
\hline leum & - & - & $\mathrm{FeCl}_{3}$ & Dark brown & Phenols X \\
\hline ether & - & - & $\mathrm{HCl}$ & - & Saponins $\mathbf{X}$ \\
\hline$\checkmark$ Chloro & - & - & $\mathrm{NH}_{4} \mathrm{OH}$ & - & FlavonoidsX \\
\hline form & - & - & $\mathrm{FeCl}_{3}$ & Yellow & Phenols X \\
\hline & 0.7941 & Green & $\mathrm{HCl}$ & Green & Saponins \\
\hline
\end{tabular}

X- Not Detected

The extract of Celastrus peniculatus and Sterculia urens evidenced several phytochemical as revealed by phytochemical studies and TLC analysis. The aqueous extract of both the plants incorporating the maximum number of phytoconstituents. Further, study to investigate the potentiality of obtained phytochemical is required.

\section{Acknowledgements:}

Authors are much thankful to Pt. Ravishankar Shukla University Raipur (C.G.) for the financial assistance. Author is also grateful to Department of Botany, Govt. D.B. Girls P.G. (Autonomous) College Raipur, (C.G.) for providing laboratory facility and to Prof. (Dr.) Nitu Harmukh (Dept. of Botany) for her valuable suggestion.

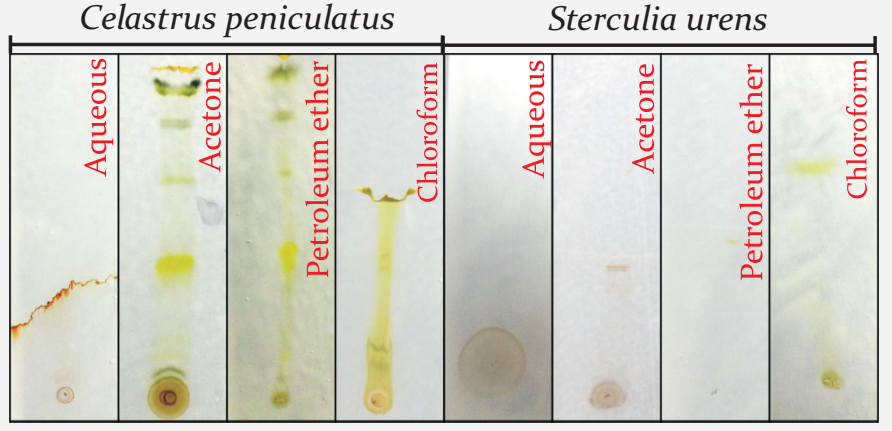

Figure-1: Thin Layer chromatography plates of different solvent extracts of $C$. peniculatus \& S. urens (before spraying reagents).

\section{References:}

Arora, N. \& Pandey-Rai, S. (2012): Celastrus peniculatus, an endangered Indian medicinal plant with miraculous cognitive and other therapeutic properties: an overview. Int.J. Pharm. BioSci., 3(3):290-303.

Cox, P.A. (1994): The ethnobotanical approach to drug discovery strengths and limitations. Ciba Found. Symp. 185:25-36.

Deodhar, K.A. \& Nandawaman, S. (2014): Phytochemical Constituents of Leaves of Celastrus peniculatus Wild: Endangered Medicinal Plant. Int. J. Pharmacog. Phytoch. Res., 6(4);792-794.

Farnsworth, N., \& Soejarto, D. (1991): Global Importance of Medicinal Plants, pp. 25-52. In O. Akerele, V. Heywood, \& H. Synge (Eds.), Conservation of Medicinal Plants. Pub. by: Cambridge University Press.

Farnsworth, N.R. (1994): Ethnopharmocology and drug development. Ciba Found. Symp., 185:42-51.

Debnath, M., Biswas, M. \& Kishteswar, K. (2012): Evaluation of analgesic activity of different leaf extracts of Celastrus paniculatus (willd.) :J.Adv. Pharm. Edu. Res., 2(2):68-73.

Hassan, L.E.A., Sirat, H.M., Yagi, S.M.A., Koko, W.S. \& Abdelwahab, S.I. (2011): In vitro antimicrobial activity of chloroformic, hexane and ethanolic extracts of Citrullus lanatus var. citroides (Wild melon): J. Med. Plants Res., 5(8):1338-1344.

Kakad, S.L. \& Dhewbara, A.J. (2017): Preliminary phytochemical screening of some medicinal plants from Bhandardhara, Maharastra. J.Zool. Stud., 4(3):57-61.

Rasid, R. \& Hajam, G.N., Wani, M.H. \& Gulzar, A. (2017): Thin Layer Chromatoraphy Profiling of the Medicinal Plant Solanum Nigrum L. from the Local Area of the District Anantnag of Jammu and Kashmir. Int. J. Adv. Res. Ideas Inno. Technol., 3(6):6-9.

Rawat, M., Singh, D., Saraf, S. \& Saraf, S. (2006): Nanocarriers: Promising vehicle for bioactive drugs. Biol. Pharm. Bull., 29(9):1790-1798.

Reddy, H.A, Sri Lakshmi, B., Nageswari, G., Shobha, R \& Venkatappa, B. (2015): Phytochemical screening, TLC fingerprinting and antimicrobial activity of methanolic leaf extracts of Aloe Vera against clinical isolates of Methicillin resistant Staphylococcus aureus. Mintage J. Pharma. Med. Sci., 5(1):16-18.

Thilagavathi, T., Rajasekar, A., Doss, V. \& Ravichandran, D. (2015): Preliminary Phytochemical screening of different solvent mediated medicinal plant extracts evaluated: Int. Res. J. Pharm., 6(4):246-248. 